\title{
UPAYA MENINGKATKAN PEMBELAJARAN PASSING BOLA VOLI DENGAN BOLA SPON PADA SISWA SDN KANUNG 02 SAWAHAN MADIUN
}

\section{Martinus Handoko Prastowo}

SDN Kanung 02 Kecamatan Sawahan, Madiun, Indonesia

Email: martinus.handoko@gmail.com

\begin{tabular}{l} 
INFO ARTIKEL \\
\hline Diterima \\
5 April 2021 \\
Direvisi \\
10 April 2021 \\
Disetujui \\
15 April 2021 \\
\hline
\end{tabular}

ABSTRACT volleyball that hopefully can be sorted interest and signed in the dream process through mini volleyball, hope can also increase the criteria of maximum completion (KKM). This research is a class step research

Keywords: initiative (PTK). This research has been conducted in two Passing through; mini generations, each ending consisting of planning, volleyball; sponge ball performing, conducting, observing and functioning. This research was a grade 4 student at SDN Kanung 02 in Sawahan Subdistrict, Madiun, which consisted of 8 sons and 8 daughters. Data on the results of learning to pass mini volleyball in student $I V$ is obtained through a test show, observation sheet used to collect data on student activities in following the learning process of passing volleyball with a spongeball. The results showed that learning to pass a mini volleyball with a sponge ball at SDN Kanung 02 can increase interest and motivation in the learning process of passing mini volleyball so that it can achieve KKM value. The improvement of the learning outcomes of grade IV students of SDN Kanung 02 in Sawahan Subdistrict, Madiun can be seen from the significant improvement of the condition of cycle I and Cycle II. The results of learning mini volleyball pasing obtained from cycle $I$ is as much as 11 students or a percentage of completion $62.5 \%$. While in cycle II there was an increase to 14 students or a percentage of completion $81.25 \%$ of the total number of students. Based on the results of the research obtained the conclusion that with a sponge ball mini volleyball game can improve the results of learning pasing mini volleyball in grade IV students SDN Kanung SDN Kanung 02 Sawahan Subdistrict Madiun.

\section{ABSTRAK}

Penelitian ini bertujuan untuk mencoba metode passing bola voli mini yang diharapkan dapat meningkatkan

$\begin{array}{ll}\text { How to cite: } & \text { Prastowo, Martinus Handoko (2021) Upaya Meningkatkan Pembelajaran Passing Bola Voli Dengan } \\ & \text { Bola Spon Pada Siswa Sdn Kanung 02 Sawahan Madiun. Jurnal Syntax Admiration 2(4). } \\ & \underline{\text { https://doi.org/10.46799/jsa.v2i4.216 }} \\ \text { E-ISSN: } & \frac{2722-5356}{\text { Ridwan Institute }} \\ \text { Published by: } & \end{array}$


Kata Kunci:

passing; bola voli mini; bola spon minat dan motivasi dalam proses pembelajaran bola voli mini, dan diharapkan dapat meningkatkan Standar Integritas Maksimum (KKM). Penelitian ini merupakan Penelitian Tindakan Kelas (PTK). Penelitian ini dilaksanakan dalam dua siklus, setiap siklus meliputi perencanaan, pelaksanaan, pelaksanaan tindakan, observasi dan refleksi. Objek penelitian ini adalah siswa kelas 16 SDN Kanung 02 Kabupaten Madiun Kabupaten Sawahan yang terdiri dari 8 putra dan 8 putri. Melalui tes unjuk kerja diperoleh data skor belajar IV siswa bola voli mini, dan tabel observasi digunakan untuk mengumpulkan data aktivitas siswa setelah pembelajaran bola voli dengan bola sponge lulus proses pembelajaran. Hasil penelitian menunjukkan bahwa hasil pembelajaran bola voli mikro dengan bola spons SDN Kanung 02 dapat meningkatkan minat dan motivasi belajar bola voli mikro, sehingga mencapai nilai KKM. Dari kondisi peningkatan yang signifikan pada siklus I dan II terlihat bahwa hasil belajar siswa kelas IV SDN Kanung 02 Kecamatan Savahan Kabupaten Medivh mengalami peningkatan. Hasil belajar passing bola voli mini yang diperoleh dari permainan ronde pertama sebanyak 11 siswa atau tingkat ketuntasan 62,5\%. Pada siklus II jumlah siswa meningkat menjadi 14 siswa yaitu tingkat ketuntasan mencapai $81,25 \%$ dari jumlah siswa. Berdasarkan hasil penelitian dapat disimpulkan bahwa penggunaan bola spon pada pertandingan bola voli mini dapat meningkatkan efek belajar pada level SDN Kanung SDN Kanung 02 Kabupaten Madiun Kecamatan Sawahan IV melalui permainan bola voli mini.

\section{Pendahuluan}

Pembelajaran pendidikan jasmani biasanya bersifat tradisional. Model pembelajaran fisika tidak harus berpusat pada guru, tetapi bagi siswa arah pembelajaran harus disesuaikan dengan tumbuh kembang anak, isi dan materinya, serta cara penyampaiannya harus disesuaikan untuk membuatnya menarik. Tujuan pembelajaran tidak hanya digunakan untuk perkembangan olahraga, tetapi juga untuk perkembangan pribadi anak (Fahrudin, 2016). Mereka yang ingin mengajar olahraga perlu memahami konsep dasar olahraga dan model olahraga yang efektif (Mulyasa, 2010).

Konsep bodi sering disalahartikan dengan desain lain. Konsep olahraga biasanya disamakan dengan segala upaya atau aktivitas yang mengarah pada perkembangan organ tubuh manusia (bodybuilding), kebugaran jasmani (physical fitness), kesibukan (physical activities), dan pengembangan keterampilan (skill development) (Ruhiatna, 2018). Pemahaman ini menambah pandangan sempit dan menyesatkan tentang arti sebenarnya dari olahraga. Walaupun aktivitas fisik memang memiliki tujuan tertentu, 
namun tidak mengandung unsur ajar karena tidak berkaitan dengan tujuan pendidikan. (Wisnawa et al., 2018). Olahraga tidak hanya merupakan kegiatan pengembangan olahraga yang terisolasi, tetapi juga harus dilaksanakan dalam rangka pendidikan umum (general education) (Pahliwandari, 2017). Untuk mencapai tujuan yang telah ditetapkan, sudah tentu proses tersebut dilakukan dengan sadar dan melibatkan interaksi sistematis antara pelakunya. Penyelenggaraan program pendidikan jasmani olahraga dan kesehatan hendaknya mencerminkan karakteristik program pendidikan jasmani itu, yaitu "developmentally appropriate" (DAP) (Kurniawan, 2015). Artinya yaitu tugas belajar yang diberikan wajib memperhatikan perubahan kemampuan anak dan dapat membantu mendorong perubahan tadi. Dengan demikian tugas ajar tadi wajib sinkron menggunakan taraf perkembangan murid yg sedang belajar. Tugas ajar yg sinkron ini wajib bisa mengakomodasi setiap perubahan yg lebih baik (Wijaya, 2018).

Pengertian pendidikan jasmani menurut para ahli. Pendidikan jasmani adalah bagian pendidikan nasional, artinya pendidikan jasmani tidak terfokus pada aspek motoriknya saja, tetapi juga terdapat aspek kognitif dan efektif (Pertama, 2010). Pendidikan jasmani adalah pendidikan melalui aktivitas yang dijadikan sebagai media untuk mencapai perkembangan individu secara menyeluruh (Abduljabar, 2011). Pendidikan jasmani merupakan proses mendidik seseorang sebagai individu atau anggota masyarakat.Prinsip tersebut dilaksanakan secara sadar dan sistematis melalui berbagai kegiatan olahraga untuk memperoleh pertumbuhan jasmani, kesehatan dan kebugaran jasmani, kemampuan dan keterampilan, perkembangan intelektual dan karakter sebagai suatu kesatuan yang harmonis. prinsip kepribadian dalam rangka membentuk pribadi yang berkualitas tinggi. (Bangun, 2016).

Pada dasarnya pembelajaran tentang olah raga dan kesehatan pendidikan jasmani di sekolah biasanya berbentuk permainan dan olah raga. Materi dan konten pembelajaran hendaknya dilakukan secara bertahap agar siswa dapat mencapai tujuan pembelajaran yang utama (Andrasari, 2010). Oleh karena itu, guru harus mengembangkan rencana pembelajaran yang mencakup pengetahuan dan keterampilan tentang strategi dan struktur pengajaran untuk meningkatkan kemampuan belajar anak. Menurut tingkat tumbuh kembang peserta didik, baik dari segi kognisi, olah raga, emosi maupun olah raga, saat ini belum ada pengelolaan yang tepat terhadap realitas bidang olah raga(Putra et al., 2018). Model pembelajaran yang tidak sesuai karakteristik anak tidak ada kreativitas akan membuat anak merasa bosan, sehingga anak tidak bergairah untuk melakukan pembelajaran, sebagai contoh pada pembelajaran voli (Saputra \& Gusniar, 2019). Belajar seringkali tidak sesuai dengan karakteristik anak, sehingga keasyikan menciptakan anak tidak terbayangkan. Hal ini membuat pembelajaran kurang memuaskan sehingga hasil belajar kurang memuaskan. Oleh karena itu diharapkan guru dapat memodifikasi konten pembelajaran yang ada agar anak tidak cepat bosan, sehingga anak bersemangat dan termotivasi untuk mengikuti kelas berikutnya. Ini membuktikan nilai belajar gagal tanpa menggunakan game yang ditingkatkan (Saputra \& Gusniar, 2019). 
Dari segi emosi, ada sebanyak 5 siswa yang tergolong dalam kategori tuntas, terhitung 26\% dari 18 siswa. Dari segi kognisi, sebanyak 10 siswa yang memenuhi standar ketuntasan atau 55\% pada bidang psikomotor saja, dan 8 siswa bidang psikis mencapai standar ketuntasan atau 45\%. Modifikasi merupakan salah satu upaya yang harus dilakukan guru agar pembelajaran mencerminkan DAP (Waluyaningsih, n.d.). Untuk itu DAP yang didalamnya memperhatikan berukuran tubuh anak didik wajib selalu sebagai prinsip primer pada memodifikasi pembelajaran pendidikan olahraga dan kesehatan. Inti dari memodifikasi merupakan menganalisa dan berbagi bahan ajar menggunakan cara meruntuhkannya pada bentuk kegiatan belajar potensial yang bisa memperlancar anak didik pada belajarnya (Rakhman, 2011).

Pengembangan pembelajaran permainan bola voli smaller seperti biasa pada pendidikan jasmani melalui modifikasi sangatlah tepat dilakukan, karena selain variasi mengajar nya banyak, penyesuaian terhadap kemampuan anak sehingga mereka tidaklah terlalu bosan mengikuti pembelajaran, termotivasi dan bergairah untuk bergerak (Ruhiatna, 2018). Proses pendidikan jasmani olahraga dan kesehatan di Sekolah Dasar Negeri Kanung 02 Sawahan Madiun kondisinya kurang sinkron ciri anak sekolah dasar, permainan-permainan mini yang mengundang tawa dan perasaan bahagia yang sebagai ciri anak sekolah dasar masih belum digali secara maksimal, sebagai akibatnya anak kurang aktif, cenderung membosankan, taktik pembelajaran yang dilakukan pula masih senantiasa memakai pendekatan drill atau perlakuan terus menerus layaknya training yg dipakai buat mencetak seseorang atlet, hal ini kurang sempurna buat dilakukan dalam pembelajaran PJOK. Oleh karena itu pembelajaran permainan bola voli kecil perlu dilakukan modifikasi dan pula perubahan pada taktik pembelajaran. Meningkatkan permainan bola volikecil dan pula memakai bola plastik yang dilapisi spon sanggup mempermudahpembelajaran \& sebagai solusi pembelajaran yang lebih bergairah dalam siswa.

Lantaran permainan ini hampir sama menggunakan permainan bola voli kecil sesungguhnya hanya saja memakai bola plastik yang dilapisi spon dan net. Oleh lantaran itu peneliti akan melakukan penelitian menggunakan judul "Upaya Meningkatkan Pembelajaran Passing Bola Voli Dengan Bola Spon Pada Siswa Sekolah Dasar Negeri Kanung 02 Sawahan Madiun”.Melalui penerapan metode bermain tujuan penelitian ini adalah untuk mencobakan metode modifikasi bola voli mini yang diharapkan dapat diterima peserta didik sehingga dapat meningkatkan minat dan motivasi terhadap proses pembelajaran passing bola voli mini sehingga diharapkan dapat pula meningkatkan kriteria ketuntasan minimal (KKM).

\section{Metode Penelitian}

Desain penelitian yang digunakan dalam penelitian ini adalah penelitian tindakan kelas (PTK) yang menggunakan data pengamatan secara langsung terhadap proses pembelajaran. Data yang diperoleh kemudian dianalisis melalui beberapa tahapan dalam siklus-siklus tahapan mulai dari observasi, wawancara, dan tes. Subjek penelitian ini adalah siswa kelas IV SDN Kanung 02 Sawahan Madiun. Subjek penelitian ini adalah 
pembelajaran dengan menggunakan bola spon pada pembelajaran passing bola voli mini yang bertujuan untuk meningkatkan hasil belajar siswa kelas IV SDN Kanung 02 Sawahan Madiun. Penelitian Tindakan Kelas (PTK) penelitian ini dilaksanakan pada tanggal 12 januari 2019 sampai dengan 16 maret 2019 jam 07.00 s/d 10.30. Kegiatan penelitian ini dilaksanakan sesuai dengan jadwal pelajaran yaitu pada setiap hari sabtu. Penelitian ini dilaksanakan di halaman SDN kanung 02 Sawahan Madiun.

Teknik pengumpulan data dalam penelitian tindakan kelas (PTK) terdiri dari tes dan observasi:

1. Observasi

Dipergunakan sebagai tehnik untuk mengumpulkan data tentang aktivitas siswa dan guru selama kegiatan belajar mengajar saat permainan dalam pembelajaran.

2. Dokumentasi

Dokumentasi diperlukan untuk mengumpulkan data dengan cara membuat lembar penilaian siswa, foto mengenai passing bola voli mini dengan bola spon yang digunakan oleh siswa kelas IV SDN Kanung 02 kecamatan Sawahan kabupaten Madiun.

3. Tes

Tes ini dipergunakan untuk mendapatkan hasil passing bola voli mini yang telah dilakukan siswa kelas IV SDN Kanung 02 kecamatan Sawahan kabupaten Madiun.

Untuk mengetahui ke efektifan suatu metode dalam kegiatan pembelajaran perlu diadakan analisis records. Pada penelitian ini menggunakan tehnik analisis deskriptif kuantitatif, yaitu suatu metode penelitian yang bersifat menggambarkan kenyataan atau fakta sesuai dengan records yang diperoleh dengan tujuan untuk mengetahui hasil belajar yang dicapai siswa untuk memperoleh respon siswa terhadap kegiatan pembelajaran serta aktivitas siswa selama proses pembelajaran passing dengan bola spon. Teknik analisa records yang digunakan dalam penelitian ini adalah records kuantitatif berupa hasil belajar kognitif, di analisis dengan menggunakan tehnik analisis deskritif presentase dengan menggunakan presentase ketuntasan belajar dan rata-rata kelas.

\section{Hasil dan Pembahasan}

A. Siklus pertama

Pelaksanaan siklus I terdiri atas empat tahap yaitu perencanaan (planning). Pelaksanaan tindakan (action), observasi, dan refleksi. Tahap-tahap yang dilaksanakan pada siklus I adalah sebagai berikut:

1. Perencanaan Tindakan

Perencanaan tindakan, sebagai berikut :

a. Membuat Rencana Pelaksanaan Pembelajaran (RPP) dengan mengacu pada tindakan yang ditetapkan dalam PTK, yaitu passing menggunakan bola spon bergabus yang digantung untuk meningkatkan hasil belajar passing bola voli mini 
b. Menyiapkan alat yang digunakan

c. Menyusun instrumen tes passing bola voli mini dan lembar observasi atau pengamatan pembelajaran melalui rubric penilaian yang tercantum pada RPP

d. Peneliti dan kolaborator menentukan lokasi

2. Pelaksanaan Tindakan

Pelaksanaan tindakan di lapangan, pertemuan dilaksanakan selama 3 x 35 menit. Tahap pelaksanaan dilakukan dengan melaksanakan skenario pembelajaran yang telah dilaksanakan sesuai dengan RPP.

Materi pada pelaksanaan tindakan siklus I, sebagai berikut:

a. Kegiatan Awal

1) Guru menyiapkan peralatan

2) Guru menyiapkan pertanyaan-pertanyaan untuk mengkolaborasi respon siswa.

3) Peneliti dan guru menyiapkan siswa dengan memulai proses pembelajaran dengan berdoa kemudian mempresensi.

4) Guru memberikan persepsi, motivasi dan penjelasan tujuan.

5) Melakukan Pemanasan

Melakukan pemanasan dengan permainan yang mengacu pada materi yang akan dipelajari, yaitu bermain kucing-kucingan dengan menggunakan bola spon.

b. Kegiatan Inti

1) Teknik dasar passing menggunakan bola voli mini. Guru menjelaskan cara melakukan gerakan passing menggunakan bola voli yang terdiri dari sikap permulaan, sikap saat perkenaan bola, serta sikap akhir yang benar.

2) Passing bola voli mini dengan permainan bola berantai.

Bola spon di tali dengan rafia dan kemudian digantung pada net ketinggiannya disesuaikan dengan tinggi siswa, siswa mempassing bola dengan passing secara berantai dari awal sampai yang paling akhir secara continue. Guru menjelaskan cara melakukan gerakan passing bola spon kemudian siswa mempraktikkannya diselingi istirahat kira2 10 menit untuk merilekskan pikiran.

c. Penutup

Melaksanakan pendinginan, evaluasi dan tanya jawab, siswa kemudian berdoa.

3. Observasi

Pengamatan dilakukan oleh peneliti bersama kolegan atau saat proses pembelajaran berlangsung. peninjauan dilakukan menggunakan lembar observasi keterampilan siswa dalam melakukan passing dengan memperhatikan 3 bidang penilaian, yaitu kognitif, afektif dan psikomotor. Hasil observasi tersebut antara lain:

a. Proses Tindakan

Pertemuan pertama pembelajaran passing bola voli mini berjalan cukup baik. Guru sudah memberikan materi dan memberi eksemplar. Namun masih banyak siswa yang gerakannya masih salah 
b. Pengaruh Tindakan

Pembelajaran bola voli mini dengan bola spon ternyata dapat mempermudah dan mengurangi rasa takut siswa terhadap passing. Perbaikan-perbaikan gerakan mulai bisa diamati menjadi lebih baik meskipun belum semuanya mengalami peningkatan.

c. Kendala dalam implementasi tindakan

Ada beberapa faktor yang dihadapi ketika pelaksanaan tindakan. Pada pertemuan pertama, siswa masih sulit ditata di awal kegiatan. Konsentrasi siswa terkadang tidak fokus, masih terdapat siswa yang tidak mencermati perintah.

d. Identifikasi penyebab terkendalanya tindakan

Kendala yang dihadapi dapat dikenal penyebabnya, tidak mutlak perhatian siswa terpaku pada pembelajaran dan kurang serius dalam mengikuti pembelajaran.

Tabel 1

Hasil Observasi Psikomotor, Afektif dan Kognitif

\begin{tabular}{|c|c|c|c|}
\hline \multirow[t]{2}{*}{ Aspek } & \multicolumn{2}{|c|}{ Siklus I } & \multirow[b]{2}{*}{ Kriteria } \\
\hline & $\%$ & Jumlah Anak & \\
\hline \multirow[b]{2}{*}{ Psikomotor } & $50 \%$ & 8 & Tuntas \\
\hline & $50 \%$ & 8 & Belum Tuntas \\
\hline \multirow[b]{2}{*}{ Afektif } & $60 \%$ & 10 & Tuntas \\
\hline & $40 \%$ & 8 & Belum Tuntas \\
\hline \multirow[b]{2}{*}{ Kognitif } & $65 \%$ & 11 & Tuntas \\
\hline & $35 \%$ & 5 & Belum Tuntas \\
\hline
\end{tabular}

4. Refleksi

Berdasarkan hasil observasi pada aktivitas pertama tersebut, peneliti melakukan kajian dan refleksi sebagai berikut:

a. Nilai Psikomotor ( Kolabolator I dan II ).

Tabel 2

Kemampuan Siswa ( Psikomotor ) Passing Siklus I

\begin{tabular}{|c|c|c|c|c|}
\hline \multirow[b]{2}{*}{ Aspek } & \multirow[b]{2}{*}{ Kolabolator } & \multicolumn{2}{|r|}{ Siklus I } & \multirow[t]{2}{*}{ Kriteria } \\
\hline & & $\%$ & Jumlah Anak & \\
\hline \multirow{4}{*}{$\begin{array}{l}\text { Penguasaan } \\
\text { Gerak }\end{array}$} & & $60 \%$ & 10 & Tuntas \\
\hline & I & $40 \%$ & 6 & Belum Tuntas \\
\hline & & $56 \%$ & 9 & Tuntas \\
\hline & II & $44 \%$ & 7 & Belum Tuntas \\
\hline
\end{tabular}

Berdasarkan tabel 2, siswa kelas IV SDN kanung 02 kecamatan Sawahan menunjukkan kenaikan hasil belajar passing bola voli mini. Siswa yang sebanyak 10 siswa atau $60 \%$, sedangkan siswa yang belum berakhir sebanyak 6 siswa atau $40 \%$ untuk kolaborator I, sedangkan kolaborator II yaitu siswa yang 
berakhir sebanyak 9 siswa atau 56\% yang belum berakhir sebanyak 7 siswa atau $44 \%$.

b. Nilai Afektif

Tabel 3

Aktivitas Siswa ( Afektif ) Passing Bola Voli Mini Siklus I

\begin{tabular}{ccccc}
\hline Aspek & \multirow{2}{*}{ Kolaborator } & \multicolumn{2}{c}{ Siklus I } & \multirow{2}{*}{ Kriteria } \\
\cline { 3 - 4 } & & $\mathbf{\%}$ & Jumlah anak & \\
\hline Penguasaan & I & $50 \%$ & 8 & Tuntas \\
\cline { 3 - 5 } Gerak & & $50 \%$ & 8 & Belum Tuntas \\
\cline { 2 - 5 } & II & $56 \%$ & 9 & Tuntas \\
\cline { 3 - 4 } & & $44 \%$ & 7 & Belum Tuntas \\
\hline
\end{tabular}

Berdasarkan Tabel 3 menunjukkan bahwa kegiatan efektif siswa dalam pembelajaran passing bola voli mini siswa kelas IV SDN Kanung 02 Sawahan menunjukkan kenaikan yaitu sebanyak 8 siswa atau 50\% dalam kriteria tuntas, sedangkan siswa yang belum tuntas sebanyak 8 orang atau $50 \%$ dalam kriteria belum tuntas untuk kolaborator I, sedangkan untuk kolaborator II yaitu sebanyak 9 siswa atau 56\% dalam kriteria tuntas dan 7 siswa atau $44 \%$ dalam parameter belum tuntas.

c. Nilai Kognitif

Tabel 4

Pemahaman Konsep ( Kognitif ) Passing Bola Voli Siklus I

\begin{tabular}{|c|c|c|c|c|}
\hline \multirow[b]{2}{*}{ Aspek } & \multirow[b]{2}{*}{ Kolaborator } & \multicolumn{2}{|r|}{ Siklus I } & \multirow[b]{2}{*}{ Kriteria } \\
\hline & & $\%$ & Jumlah Anak & \\
\hline \multirow{4}{*}{$\begin{array}{c}\text { Penguasaan } \\
\text { Gerak }\end{array}$} & & $64 \%$ & 10 & Tuntas \\
\hline & I & $36 \%$ & 6 & Belum Tuntas \\
\hline & \multirow[b]{2}{*}{ II } & $60 \%$ & 9 & Tuntas \\
\hline & & $40 \%$ & 7 & Belum Tuntas \\
\hline
\end{tabular}

Berdasarkan Tabel 4 dapat disimpulkan bahwa pemahaman konsep tentang materi passing kelas IV SDN kanung 02 kecamatan Sawahan menunjukkan kenaikan yaitu sebanyak 10 siswa atau $64 \%$ dalam kriteria tuntas, sedangkan siswa yang belum tuntas sebanyak 6 siswa atau 36\% dalam kriteria belum tuntas untuk kolaborator I, sedangkan untuk kolaborator II yaitu sebanyak 9 siswa atau $60 \%$ dalam kriteria tuntas dan 7 siswa atau $40 \%$ dalam kriteria belum tuntas.

d. Hasil Belajar

\section{Tabel 5}

Deskripsi Hasil Belajar Passing Bola Voli Mini Siklus I

\begin{tabular}{cccc}
\hline Aspek & \multicolumn{2}{c}{ Siklus I } & Kriteria \\
\hline $\begin{array}{c}\text { Penguasaan Passing } \\
\text { Bola Voli Mini }\end{array}$ & Presentase & Jumlah Anak & Tuntas \\
\cline { 2 - 3 } \\
\cline { 2 - 3 }
\end{tabular}




\begin{tabular}{lll}
\hline $37 \%$ & 6 & Belum Tuntas \\
\hline
\end{tabular}

Berdasarkan data hasil belajar kegiatan siklus I yang dihasilkan, dapat diketahui bahwa nilai yang menunjukkan ketuntasan $63 \%$ atau 10 orang dari jumlah keseluruhan,ini berarti 6 siswa atau 37\% belum mencapai KKM yaitu 75 jumlah siswa yang mendapatkan nilai diatas 75 menjadi bukti kenaikan hasil belajar passing bola voli mini SDN kanung 02 Sawahan. Dari tabel diatas bila digambarkan dalam bentuk diagram, sebagai berikut:

B. Ketuntasan Hasil Belajar Siswa Kelas IV SDN Kanung 02 Pada Siklus I

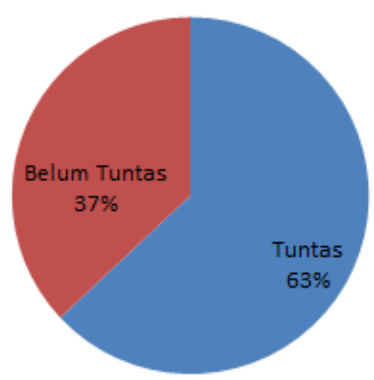

Diagram 1

\section{Diagram Ketuntasan Hasil Belajar Siswa Kelas IV Siklus I Siklus Kedua}

Siklus II merupakan tindak lanjut dari hasil analisis dan refleksi siklus I, dimana dalam pelaksanaan tindakan siklus I rata-rata siswa menunjukkan hasil yang kurang maksimal dan belum sesuai dengan parameter yang telah ditetapkan. Pelaksanaan siklus II mengacu pada pelaksanaan siklus I, karena merupakan perbaruan dari siklus I, Adapun tahap yang dilakukan pada siklus II yaitu:

1. Perencanaan Tindakan

Perencanaan adalah sebagai berikut:

a. Peneliti membuat agenda pelaksanaan pembelajaran (RPP) dengan mengacu pada tindakan yang diterapkan dalam PTK, dan berdasarkan apa yang telah terjadi di siklus I, menyiapkan alat yang digunakan.

b. Menyiapkan permainan yang lebih menarik dan mudah dilaksanakan untuk mengakomodasi pembelajaran passing yaitu dengan melebihkan tanda di bawah bola gantung untuk letak kaki pada waktu melaksanakan passing.

c. Menyusun instrumen tes passing bola voli mini dan lembar observasi atau pengamatan pembelajaran melalui rubrik penilaian yang tercantum pada RPP.

2. Pelaksanaan Tindakan

Pelaksanaan tindakan siklus II dilaksanakan di lapangan. Pertemuan dilaksanakan selama 3x35 menit. Tahap pelaksanaan dilakukan dengan melaksanakan skema pembelajaran yang telah direncanakan dalam RPP. Materi pada pelaksanaan aktivitas siklus II, implementasinya sebagai berikut:

a. Kegiatan Awal 
1) Guru mempersiapkan peralatan

2) Guru mempersiapkan pertanyaan-pertanyaan untuk memaparkan respon siswa

3) Peneliti dan guru mempersiapkan siswa dengan memulai proses pembelajaran dengan berdoa kemudian mempresentasi

4) Guru memberikan kesan, motivasi dan definisi tujuan

5) Melaksanakan pemanasan

Pemanasan yang diberikan berupa penguluran dan juga pemanasan dalam bentuk permainan. Peserta didik dibagi menjadi 4 kelompok, setiap kelompok membuat lingkaran diambil salah satu siswa sebagai kucing. Tugas siswa membentuk lingkaran adalah melempar bola dari bawah seperti gerakan passing kepada teman lain, jangan sampai bola ditangkap kucing. Jika bola ditangkap kucing, maka ia yang menggantikan sebagai kucing dan seterusnya.

b. Kegiatan Inti

1) Gerakan Dasar Passing Bawah Bola Voli Mini

Guru menjelaskan cara melakukan gerakan passing menggunakan bola voli mini yang terdiri dari sikap awal, bentuk saat perkenaan bola, serta sikap akhir yang benar. Siswa melakukan passing dari gerakan awal hingga akhir dalam posisi berdiri, dilakukan secara bergantian. Satu siswa pengumpan yang nanti bergilir sebagai pemassing.

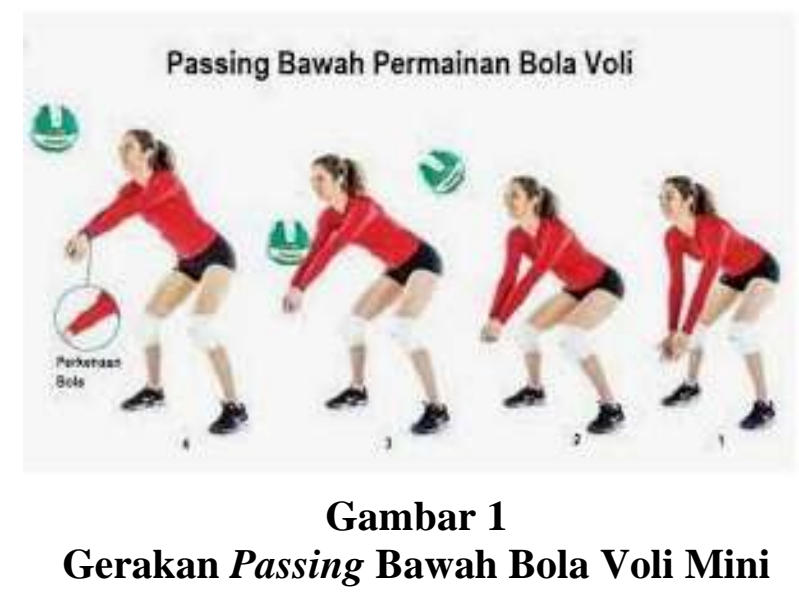

2) Gerak Dasar Passing Atas

Perkenaan bola pada jari adalah di ruas pertama dan kedua atau bagian tepat jari (bukan ujung jari), jari-jari tangan secara kelengkapan membentuk suatu setengah lingkaran dan jari-jari direnggangkan sedikit satu dengan yang lain dengan ibu jari membentuk sudut, penempatan jari-jari yang benar akan membuat gesekan pada bola menjadi merata oleh semua jari. Kedudukan jari-jari berada tepat di depan wajah dan perkenaan bola tepat pula di depan wajah. 


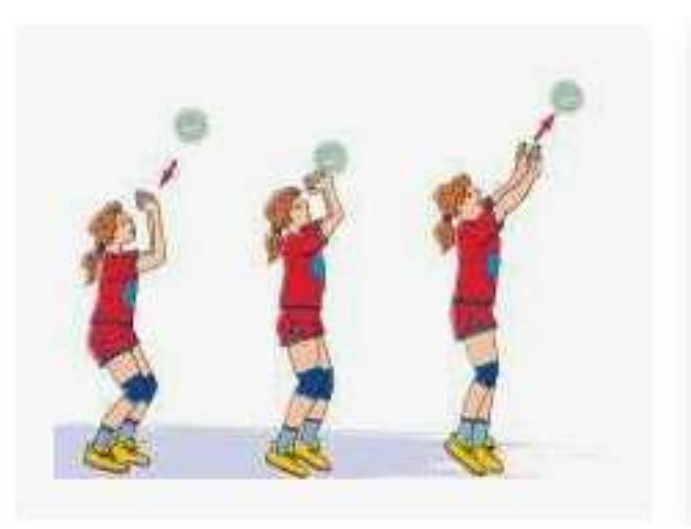

\section{Gambar 2}

Gerakan Passing Atas

3) Passing bola voli mini melalui permainan bola berantai

Guru memaparkan cara melakukan gerakan passing menggunakan bola spon di tali dengan rafia dan digantung sedangkan di bawah diberi tanda untuk posisi kaki dengan benar dan memberikan contoh gerakan, kemudian peserta didik mempraktikkan passing individu dengan permainan bola berantai, diman siswa memukul bola bergantian secara continue sampai paling akhir.

c. Penutup

Melakukan pendinginan, catatan dan tanya jawab kepada siswa dan kemudian dilanjutkan dengan berdoa.

3. Observasi

Pengamatan dilakukan oleh peneliti bersama kolaborator saat proses pembelajaran aktif. Observasi dilakukan menggunakan lembar observasi kapabilitas siswa dalam melakukan passing dengan mencermati 3 bagian penilaian yaitu kognitif, afektif dan psikomotor. Hasil observasi tersebut adalah sebagai berikut:

a. Proses Tindakan

Pertemuan pada siklus II tindakan yang telah berjalan dengan lancar. Guru sudah menyediakan materi dengan baik. Peserta didik juga dapat dikondisikan dengan baik. Pembelajaran berlangsung menarik dengan permainan bola berantai. Semua siswa mengikuti pengkajian dari awal hingga akhir tindakan. Masih ada beberapa siswa yang kadang-kadang kurang benarbenar melakukan.

b. Pengaruh Tindakan

Passing bola voli mini telah diamati dapat pengembangkan hasil belajar siswa.

c. Kendala dalam implementasi tindakan

Ada beberapa kendala misalnya siswa kurang benar-benar dalam melakukan passing.

d. Identifikasi penyebab terkendalanya aktifitas 
Identifikasi penyebab ketika ada siswa yang kurang benar-benar misalnya dilakukan dengan tertawa sehingga mengganggu konsentrasi dalam melakukan passing.

Tabel 6

Hasil Observasi Aspek Psikomotor, Afektif, dan Kognitif

\begin{tabular}{|c|c|c|c|}
\hline \multirow[t]{2}{*}{ Aspek } & \multicolumn{2}{|c|}{ Siklus II } & \multirow[t]{2}{*}{ Kriteria } \\
\hline & $\%$ & Jumlah Anak & \\
\hline \multirow[t]{2}{*}{ Psikomotor } & $84 \%$ & 13 & Tuntas \\
\hline & $16 \%$ & 3 & Belum Tuntas \\
\hline \multirow[t]{2}{*}{ Afektif } & $78 \%$ & 12 & Tuntas \\
\hline & $22 \%$ & 4 & Belum Tuntas \\
\hline \multirow[t]{2}{*}{ Kognitif } & $75 \%$ & 11 & Tuntas \\
\hline & $25 \%$ & 5 & Belum Tuntas \\
\hline
\end{tabular}

4. Refleksi

Berdasarkan hasil observasi pada tindakan pertama tersebut, peneliti melakukan analisis dan refleksi sebagai berikut:

a. Nilai Psikomotor

Tabel 7

Kemampuan Siswa ( Psikomotor ) Passing Siklus II

\begin{tabular}{|c|c|c|c|c|}
\hline \multirow[b]{2}{*}{ Aspek } & \multirow[b]{2}{*}{ Kolaborator } & \multicolumn{2}{|c|}{ Siklus II } & \multirow[b]{2}{*}{ Kriteria } \\
\hline & & $\%$ & Jumlah anak & \\
\hline \multirow{4}{*}{$\begin{array}{l}\text { Penguasaan } \\
\text { Gerak }\end{array}$} & & $69 \%$ & 11 & Tuntas \\
\hline & I & $31 \%$ & 5 & Belum Tuntas \\
\hline & & $78 \%$ & 12 & Tuntas \\
\hline & II & $22 \%$ & 4 & Belum Tuntas \\
\hline
\end{tabular}

Berdasarkan tabel 7 siswa kelas IV SDN Kanung 02 Sawahan menunjukkan kenaikan hasil belajar passing bola voli mini. Siswa yang selesai sebanyak 10 siswa atau $63 \%$ untuk kolaborator 1, sedangkan kolaborator II sebanyak 6 siswa $37 \%$ dalam kriteria belum selesai.

b. Nilai Afektif

Tabel 8

Aktivitas Siswa (Afektif) Passing Bola Voli Mini Siklus II

\begin{tabular}{ccccc}
\hline & & \multicolumn{2}{c}{ Siklus II } & \\
\cline { 3 - 4 } Aspek & Kolaborator & $\mathbf{\%}$ & Jumlah Anak & Kriteria \\
\hline \multirow{2}{*}{$\begin{array}{c}\text { Penguasaan } \\
\text { Gerak }\end{array}$} & & $78 \%$ & 12 & Tuntas \\
\cline { 3 - 5 } & I & $22 \%$ & 4 & Belum Tuntas \\
\hline & II & $84 \%$ & 13 & Tuntas \\
\hline
\end{tabular}

Berdasarkan Tabel 8 menjabarkan bahwa kegiatan afektif siswa dalam pembelajaran passing bola voli mini kelas IV SDN kanung 02 menunjukkan kenaikan yaitu sebanyak 12 orang atau $78 \%$ dalam parameter tuntas, sedangkan siswa yang belum tuntas sebanyak 4 siswa atau $22 \%$ dalam parameter belum selesai untuk kolaborator I. 
c. Nilai Kognitif

\section{Tabel 9}

Pemahaman Konsep (Kognitif) Passing Bola Voli Siklus II

\begin{tabular}{|c|c|c|c|c|}
\hline \multirow[t]{2}{*}{ Aspek } & \multirow[t]{2}{*}{ Kolaborator } & \multicolumn{2}{|c|}{ Siklus II } & \multirow[t]{2}{*}{ Kriteria } \\
\hline & & $\%$ & Jumlah Anak & \\
\hline \multirow{4}{*}{$\begin{array}{l}\text { Penguasaan } \\
\text { Gerak }\end{array}$} & & $81 \%$ & 13 & Tuntas \\
\hline & I & $19 \%$ & 3 & Belum Tuntas \\
\hline & & $82 \%$ & 13 & Tuntas \\
\hline & II & $18 \%$ & 3 & Belum Tuntas \\
\hline
\end{tabular}

Berdasarkan tabel 9 dapat disimpulkan bahwa pemahaman konsep tentang materi passing siswa kelas IV SDN Kanung 02 Sawahan menunjukkan peningkatan yaitu sebanyak 11 siswa atau 69\% dalam parameter selesai, sedangkan siswa yang belum selesai sebanyak 5 siswa atau 31\% dalam parameter belum selesai untuk kolaborator I, sedangkan kolaborator II sebanyak 12 siswa atau $78 \%$ dalam parameter selesai dan 4 siswa atau $22 \%$ dalam kriteria belum selesai.

d. Hasil Belajar

\section{Tabel 10}

Deskripsi Hasil Belajar Passing Bola Voli Mini Siklus II

\begin{tabular}{|c|c|c|c|}
\hline \multirow[b]{2}{*}{ Aspek } & \multicolumn{2}{|c|}{ Siklus II } & \multirow[b]{2}{*}{ Kriteria } \\
\hline & Presentase & Jumlah Anak & \\
\hline \multirow{2}{*}{$\begin{array}{c}\text { Penguasaan } \\
\text { Passing Bola } \\
\text { Voli }\end{array}$} & $82 \%$ & 13 & Tuntas \\
\hline & $18 \%$ & 3 & Belum tuntas \\
\hline
\end{tabular}

Berdasarkan data hasil belajar tindakan siklus II yang diperoleh, dapat diketahui bahwa nilai yang menunjukkan ketuntasan $82 \%$ atau 13 siswa dari jumlah keseluruhan. Ini berarti 3 atau 18\% belum mencapai KKM yaitu nilai 75 menjadi bukti peningkatan hasil belajar passing bola voli siswa kelas IV SDN Kanung 02 Sawahan. Dari tabel diatas bila digambar dalam bentuk diagram penyelesaian hasil belajar adalah sebagai berikut:

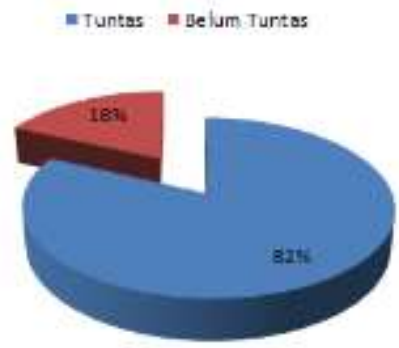

Diagram 2

Diagram Ketuntasan Hasil Belajar Siswa Kelas IV SDN Kanung 02 Sawahan Siklus II 
Perbandingan hasil aktivitas Siklus I dan Siklus II berdasarkan hasil pelaksanaan penelitian tindakan kelas (PTK) pada siswa kelas IV SDN Kanung 02 Sawahan dari siklus I ke siklus II disajikan dalam bentuk tabel sebagai berikut:

Tabel 11

\begin{tabular}{ccccc}
\multicolumn{2}{c}{ Perbandingan Hasil Belajar Passing } & \multicolumn{3}{c}{ Bola Voli Siklus I dan II } \\
\hline & \multicolumn{2}{c}{ Siswa Tuntas } & \multicolumn{2}{c}{ Siswa Belum Tuntas } \\
\cline { 2 - 5 } Tindakan & Jumlah & $\%$ & Jumlah & $\%$ \\
\hline Siklus I & 10 & $63 \%$ & 6 & $37 \%$ \\
\hline Siklus II & 13 & $81 \%$ & 3 & $19 \%$ \\
\hline
\end{tabular}

Berdasarkan tabel 11 dapat diketahui bahwa pada siklus I siswa yang tuntas ada 13 siswa atau $81 \%$, yang tidak selesai 3 siswa atau $19 \%$ yang belum selesai. Sedangkan pada siklus II siswa yang selesai adalah 13 atau $82 \%$ dan yang belum selesai 3 atau $18 \%$. Histogram perbandingan siklus I dan siklus II dapat dilihat sebagai berikut:

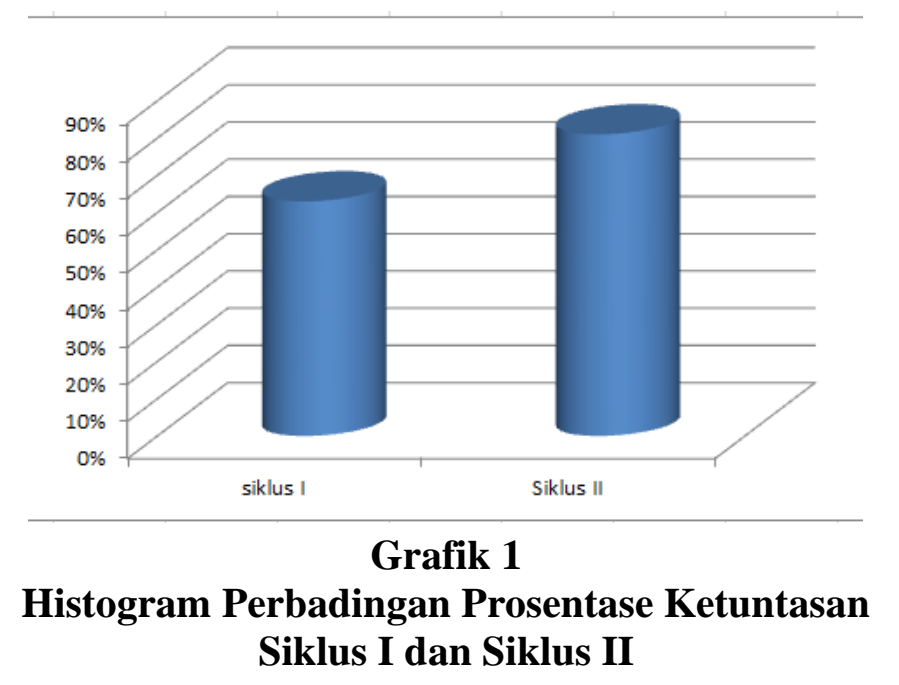

\section{Kesimpulan}

Hasil penelitian menunjukkan hasil belajar passing bola voli mini dengan bola spon SDN Kanung 02 Sawahan dapat kenaikan minat dan motivasi terhadap proses pembelajaran passing bola voli mini sehingga dapat mencapai nilai KKM. Peningkatan hasil belajar siswa kelas V SDN Kanung 02 Sawahan dapat dilihat dari masing-masing aspek selama siklus I dan siklus II. Nilai Psikomotor mencapai KKM sebanyak 59\%, sedangkan pada siklus II mencapai 69\%. Hasil evaluasi afektif selama siklus I sebanyak $50 \%$ dan mengalami peningkatan pada siklus II menjadi 78\%. Sedangkan nilai kognitif selama siklus I sebanyak 36\% dan mengalami kenaikan pada siklus II menjadi $81 \%$. 
Upaya Meningkatkan Pembelajaran Passing Bola Voli Dengan Bola Spon Pada Siswa Sdn Kanung 02 Sawahan Madiun

\section{BIBLIOGRAFI}

Abduljabar, B. (2011). Pengertian Pendidikan Jasmani. Diakses Tanggal, 17. Google Scholar

Andrasari, V. (2010). Perbedaan Pengaruh Metode Pembelajaran Dan Koordinasi Mata-Tangan Terhadap Hasil Belajar Smash Normal Bola Voli Pada Siswa Putra Kelas Viii Smp Negeri 2 Ngadirojo Wonogiri Tahun Pelajaran 2009/2010. Google Scholar

Bangun, S. Y. (2016). Peran Pendidikan Jasmani Dan Olahraga Pada Lembaga Pendidikandi Indonesia. Publikasi Pendidikan, 6(3). Google Scholar

Fahrudin, T. (2016). Upaya Peningkatan Passing Bawah Bola Voli Melalui Pendekatan Lempar Tangkap Bola Pada Siswa Kelas V Sd Negeri Banyuwangi 3 Kecamatan Bandongan Kabupaten Magelang Tahun 2015/2016. Universitas Negeri Semarang. Google Scholar

Kurniawan, D. (2015). Pengaruh Modifikasi Permainan Bolavoli Terhadap Kerjasama Siswa Pada Pembelajaran Pendidikan Jasmani, Olahraga Dan Kesehatan (Studi Pada Siswa Kelas X Boga 1 Smkn 3 Probolinggo). Jurnal Pendidikan Olahraga Dan Kesehatan, 3(1). Google Scholar

Mulyasa, E. (2010). Penelitian Tindakan Kelas. Bandung: Pt Remaja Rosdakarya. Google Scholar

Pahliwandari, R. (2017). Penerapan Teori Pembelajaran Kognitif Dalam Pembelajaran Pendidikan Jasmani Dan Kesehatan. Jurnal Pendidikan Olah Raga, 5(2), 154-164. Google Scholar

Pertama, S. M. (2010). Pendidikan Jasmani Olahraga Dan Kesehatan. Google Scholar

Putra, R. E., Putra, A. M., \& Emisnawati, E. (2018). Meningkatkan Proses Belajar Siswa Pada Mata Pelajaran Pendidikan Jasmani Dengan Materi Passing Bawah Bola Voli Mini Melalui Pembelajaran Kooperatif Model Stad Pada Siswa Kelas V Sd Negeri 168/Ii Sumber Mulya Kabupaten Bungo. Jurnal Muara Olahraga, 1(1), 87-97. Google Scholar

Rakhman, A. (2011). Modifikasi Permainan Bola Voli Dalam Pembelajaran Penjasorkes Untuk Menigkatkan Minat Siswa Putri Sma N 1 Kramat Tegal Tahun 2010. Universitas Negeri Semarang. Google Scholar

Ruhiatna, Y. (2018). Upaya Meningkatkan Hasil Belajar Passing Bola Voli Mini Dengan Bola Plastik Sekolah Dasar Negeri Kertasari Kecamatan Ligung Kabupaten Majalengka. Jurnal Elementaria Edukasia, 1(2). Google Scholar 
Saputra, D. I. M., \& Gusniar, G. (2019). Meningkatkan Hasil Belajar Passing Bawah Bola Voli Melalui Bermain Melempar Bola. Gelanggang Olahraga: Jurnal Pendidikan Jasmani Dan Olahraga, 3(1), 64-73. Google Scholar

Waluyaningsih, J. (N.D.). Meningkatkan Hasil Belajar Permainan Bola Voli Melalui Modifikasi Bola Voli Mini Siswa Kelas Iv Sdn Klatakan 02 Kecamatan Tanggul Kabupaten Jember Tahun Pelajaran 2013/2014. Google Scholar

Wijaya, I. (2018). Professional Teacher: Menjadi Guru Profesional. Cv Jejak (Jejak Publisher). Google Scholar

Wisnawa, K., Parwata, I. G. L. A., \& Spyanawati, N. L. P. (2018). * Penerapan Model Pembelajaran Koperatif Tipe Numbered Head Together (Nht) Untuk Meningkatkan Aktivitas Dan Hasil Belajar Teknik Dasar Passing Control Sepak Bola Pada Siswa Kelas Xi Ipa Sma Negeri 2 Mendoyo Tahun Pelajaran 2016/2017. Jurnal Pendidikan Jasmani, Olahraga Dan Kesehatan Undiksha, 5(2). Google Scholar

Copyright holder :
Martinus Handoko Prastowo (2021)

First publication right :

Journal Syntax Admiration

This article is licensed under: 